\title{
Uric Acid, Vascular Stiffness, and Chronic Kidney Disease: Is There a Link?
}

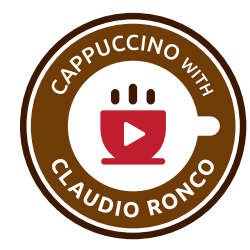

\author{
Juan C. Ramirez-Sandoval ${ }^{a} \quad$ L. Gabriela Sanchez-Lozada ${ }^{b}$ Magdalena Madero ${ }^{b}$ \\ anstituto Nacional de Ciencias Médicas y Nutrición Salvador Zubirán (National Institute of Medical Sciences and

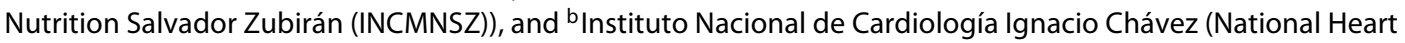 \\ Institute), Mexico City, Mexico
}

\section{Key Words}

Hyperuricemia · Hypertension - Vascular calcification · Kidney failure - Urate-lowering therapy

\begin{abstract}
Controversy exists with regard to the causal role of hyperuricemia in chronic kidney disease. Vascular stiffness may be the link that explains the relation between hyperuricemia and kidney disease. Hyperuricemia is associated with a number of effects on the vascular endothelium and vascular smooth muscle cells, including an increase in oxidative stress, production of vasoconstrictors, and changes on the structural properties of the large artery wall. Observational evidence in large epidemiological cross-sectional studies suggests that there is an independent association between uric acid and arterial stiffness. The limited evidence from cohort studies or clinical trials does not support treatment of hyperuricemia to reduce vascular stiffness in order to prevent kidney disease. Nevertheless, vascular stiffness may be a valid, reproducible, and useful surrogate endpoint. At this point there seems to be sufficient evidence to warrant larger clinical trials to determine whether lowering uric acid concentrations would be useful for prevention or treatment of vascular stiffness and, subsequently, of cardiovascular and kidney diseases.
\end{abstract}

Video Journal Club 'Cappuccino with Claudio Ronco' at http://www.karger.com/?doi=452726. @ 2017 S. Karger AG, Basel

\section{KARGER}

(c) 2017 S. Karger AG, Basel

E-Mail karger@karger.com

www.karger.com/bpu

\section{Introduction}

Hyperuricemia is a very common biochemical finding associated with aging, hypertension, chronic kidney disease (CKD), and cardiovascular disease (CVD) [1]. Nevertheless, the evidence for a causal link between hyperuricemia and these disorders is controversial, and it has not been firmly established [2]. Particularly, hyperuricemia in persons with CKD appears to be associated with an increased risk for cardiovascular and all-cause-mortality, but the role of serum uric acid (SUA) in the initiation, progression, and development of kidney failure remains questionable [3].

Arterial stiffness could be one of the possible mechanisms by which hyperuricemia increases the risk of CKD and CVD through a pathway that involves changes in vascular elastic properties, hypertension and organ damage [4]. This review summarizes relevant studies concerning SUA and vascular stiffness and possible links to the pathogenesis and progression of CKD.

\section{Vascular Stiffness as the Link between Hyperuricemia and CKD}

Arterial stiffness may be an early marker of CVD, as it predicts cardiovascular events in patients with essential hypertension and CKD [5]. Because large-vessel arterial stiffness is common in CKD, it is believed to be one of the 


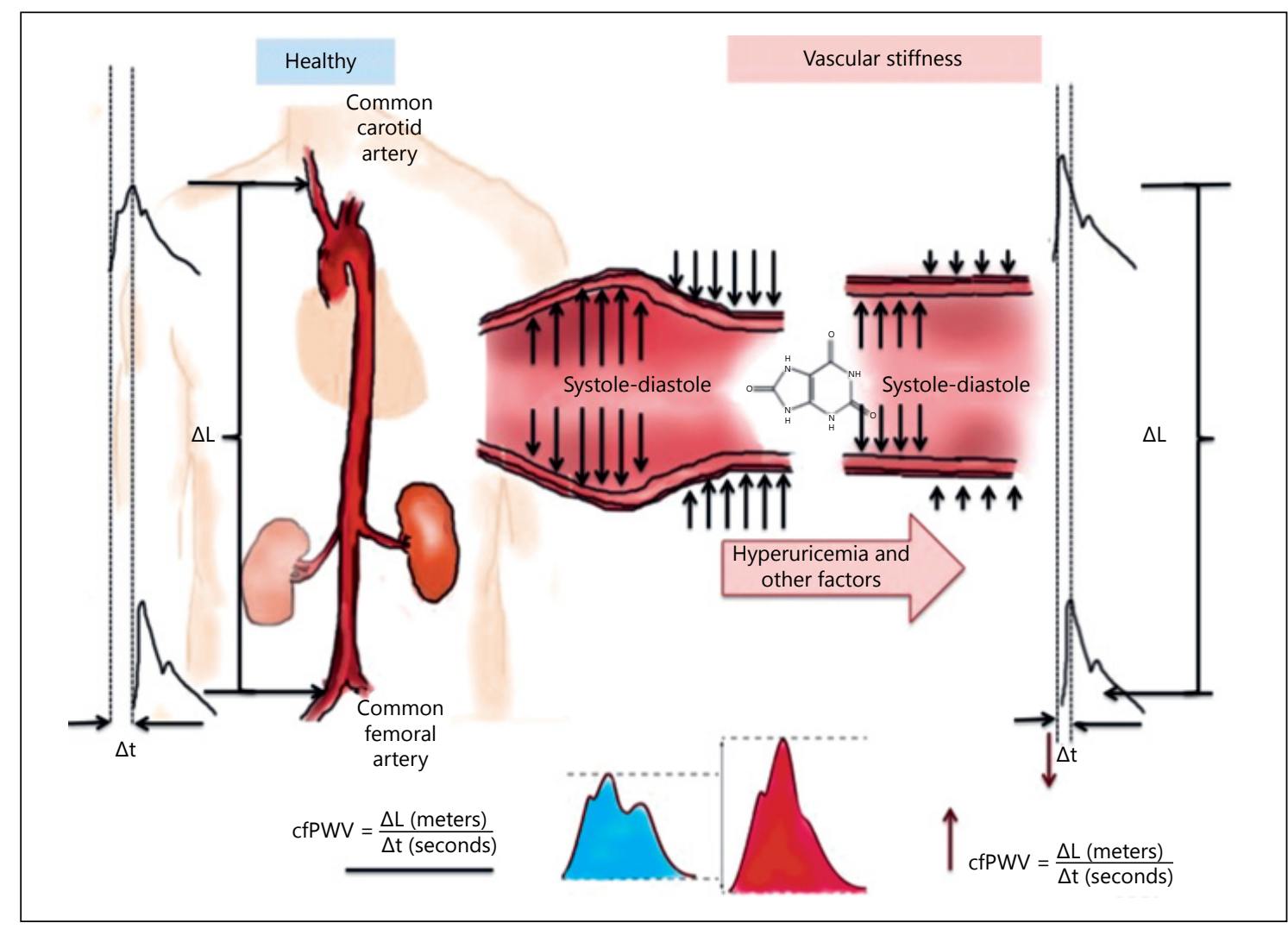

Fig. 1. Estimation of PWV in healthy individuals and in those who have hyperuricemia-induced vascular stiffness (see text for details).

mechanisms accounting for the increased risk of CVD in CKD. Vascular stiffness, independent of mean arterial pressure, establishes end-organ damage by increasing the recruitment of collagen fibers and progressive elastic fiber degeneration [6]. The stiffening process facilitates the transmission of excessive pressure and flow pulsatility, which may damage microcirculation, especially in a high-flow organ such as the kidney, leading to potentially microvascular ischemia and tissue damage [7]. Systemic pulsatile pressure can cause vascular injury in low-resistance, high-flow end organs, such as the kidney and brain [8]. There are different mechanisms suggesting a causal role of arterial stiffness in CKD. A possible hypothesis is that the changes in hemodynamic stress on the kidney vasculature may result in endothelial inflammation, infiltration of vascular smooth muscle cells and macrophages, fibrosis, deposition of mucoid material, focal media smooth muscle cell necrosis and vascular calcification [9, 10]. Other plausible mechanisms are related to the effects of chronic inflammation and activation of the renin-angiotensin system [11].
Vascular stiffness is usually estimated using the arterial pulse wave velocity (aPWV) between 2 predefined sites of the arterial system such as carotid-femoral, carotid-radial, or carotid-ankle; the time delay of the arrival of the foot of the pulse wave at these 2 sites is obtained by gating to the $\mathrm{R}$ wave of the ECG. Figure 1 shows aPWV in healthy vessels and in vascular stiffness [12]. Different cut-off values have been proposed according to the type of aPWV [13]; unfortunately, a clear international nomenclature is not commonly used, and so analysis and comparison between studies cannot be carried out with ease. Other measurements such as aortic augmentation index (AI) may not be the ideal parameter of arterial stiffness as aPWV , since it is modified by left ventricular ejection fraction and heart rate [14]. Pulse pressure, which is the difference between systolic and diastolic pressures, is one of the simplest measures of vascular stiffness, but it is inaccurate, given the problems related to the normal amplification of the pressure wave and that assessment of pulse pressure in the periphery does not reflect the actual central pulse pressure [15] . 
Several observational studies have demonstrated the association of vascular stiffness with decline in kidney function [8,16-18]. Since aortic stiffness is highly prevalent in CKD and predicts CVD events and SUA is associated with vascular disease, the relationship between UA and vascular disease could explain in part the association between the vascular stiffness and CKD.

\section{SUA and Vascular Disease: Mechanisms of Disease}

SUA may have a role in the initiation of vascular stiffness and, therefore, also a role in causing vascular disease, hypertension, and CKD. The occurrence of vascular disease may be explained by the following mechanisms: (i) uric acid gains entry to vascular endothelial cell and vascular smooth muscle cells through urate-anion exchangers such as URAT-1, which is expressed in endothelial cells and not only in kidney tubular cells [19]; (ii) high uric acid in the intracellular compartment induces several mechanisms of cellular damage by increasing the activity of nicotinamide adenine dinucleotide phosphate oxidase, which produces reactive oxygen-species and decreases the bioavailability of nitric oxide (NO) [20]; (iii) uric acid activates the transcription factors nuclear factor- $\kappa \mathrm{B}$, activator protein-1, the mitogen-activated protein kinase signaling molecules ERK p44/42 and p38, and increases cyclooxygenase- 2 mRNA expression in cultured vascular smooth-muscle cells [21]; (iv) oxidative stress induced by uric acid also activates the Notch-1 pathway in a dose- and time-dependent manner, which plays an important role in inflammation [22]; (v) uric acid stimulates increased production of the chemokine monocyte chemoattractant protein 1 (MCP-1) expression in a time- and dose-dependent manner dependent on posttranscriptional modification of MCP-1 mRNA [21]; (vi) urate-induced oxidative stress increases the production of potent vasoconstrictors such as endothelin-1 [23]; (vii) uric acid stimulates the local vascular renin-angiotensin system through the activation of mitogen-activated protein (MAP) kinase pathway. The activation of the renin-angiotensin system and reduction of NO synthesis promotes endothelial dysfunction [24]. All these inflammatory pathways may play a role in the process of arterial stiffening even in health; (viii) arterial stiffness relies on the structural properties of the large artery wall, including its essential protein, elastin. Polymers of elastin are the major extracellular matrix components deposited mainly by vascular smooth muscle cells in the arterial media providing 'elasticity' to the aorta and resilience against the hemodynamic stresses of the dis-

Hyperuricemia, Vascular Stiffness and CKD tending pressure [25]. Hyperuricemia may affect the natural turnover of non-cross-linked soluble elastin, a potential indicator of eventual vascular stiffness [26]. Finally, in the kidney, hyperuricemia-induced microvascular damage to afferent arterioles may lead to the occurrence of sodium-sensitive hypertension [27]. In this condition, increased hypertension would induce more vascular stiffness that would increase blood pressure, which would become a vicious circle with time.

\section{UA and Vascular Stiffness: Observational Studies}

Numerous epidemiological studies have described a link between hyperuricemia and CVD. Recently, Borghi et al. [28] conducted a comprehensive review of hyperuricemia and cardiovascular morbidity and/or mortality; however, most of these studies did not include vascular stiffness as a surrogate endpoint. To define the role of SUA in vascular stiffness, we summarized observational studies that report an association between vascular stiffness and hyperuricemia (table 1). Four large epidemiological transversal studies including more than 1,000 patients with differences in clinical characteristics showed a positive association between SUA and vascular stiffness, assessed for the most part by carotid-femoral PWV (cfPWV) [29-32]. In one study from Framingham Heart Study Gen III Cohort, each $1 \mathrm{mg} /$ dl increase in SUA was associated with higher cfPWV) [29]. Most of the studies that did not find an association in healthy individuals or in subjects without a history of CKD, $\mathrm{CVD}$, or diabetes. The possible explanation behind these apparently discrepant findings may be that hyperuricemia is a stronger risk factor for vascular stiffness only if a second 'hit' has occurred. Several difficulties in determining whether SUA per se should be considered a causal factor for vascular stiffness since most of the studies had a crosstransversal design with potential residual confounding. To our knowledge, there are no cohort studies where the exposure ('hyperuricemia') could be assessed prior to the occurrence of vascular stiffness or CKD.

\section{UA and Vascular Disease: Interventional Studies}

Three parallel randomized, double-blind studies have tested the effect of allopurinol in vascular stiffness in subjects with stage 3 CKD [33], diabetes mellitus [34], and patients with ischemic heart disease (IHD) without CKD [35]. In each of these studies, 67 or 66 patients were assigned to allopurinol $600 \mathrm{mg} /$ day for 9 months vs. placebo. Treat- 


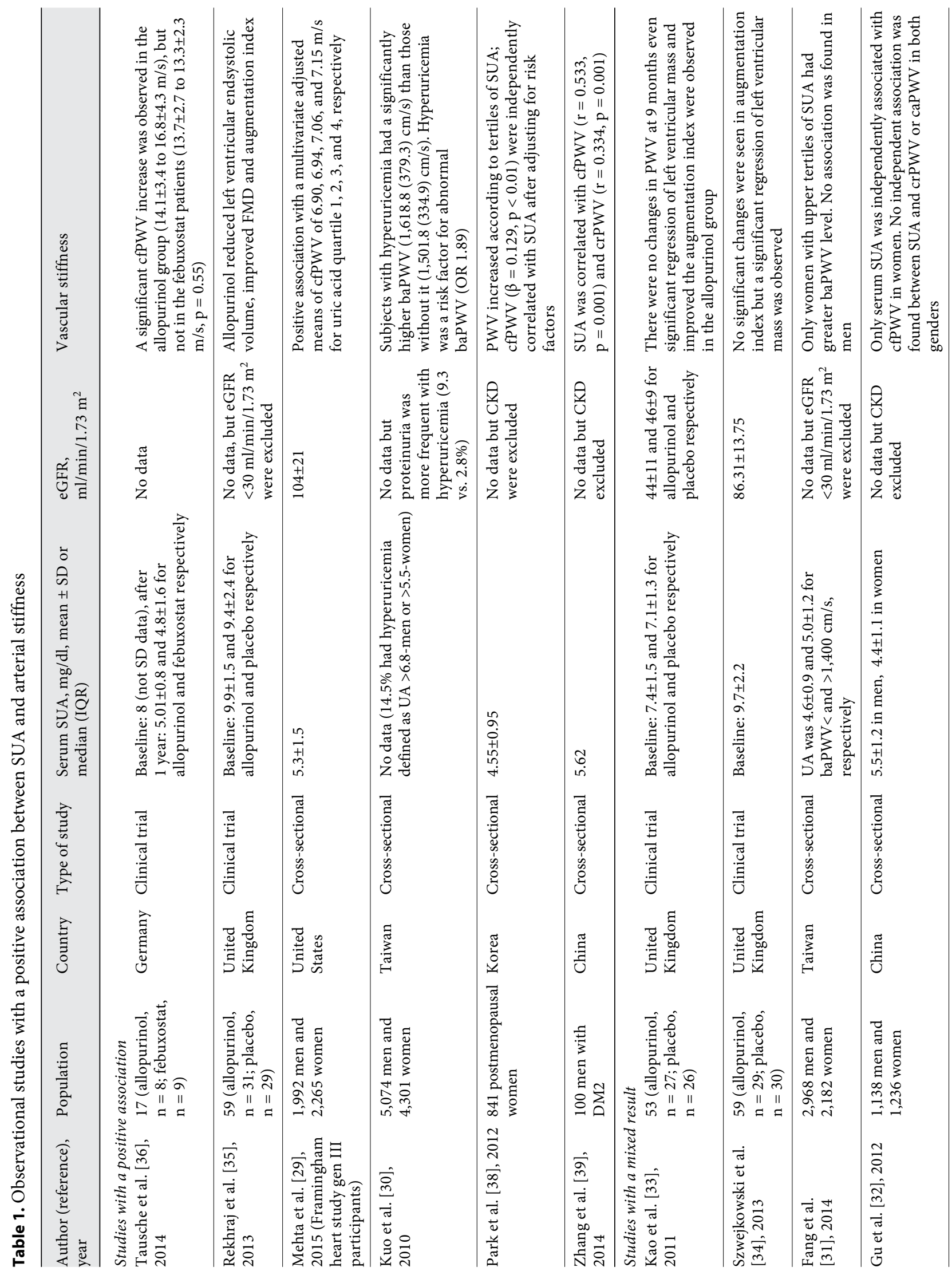




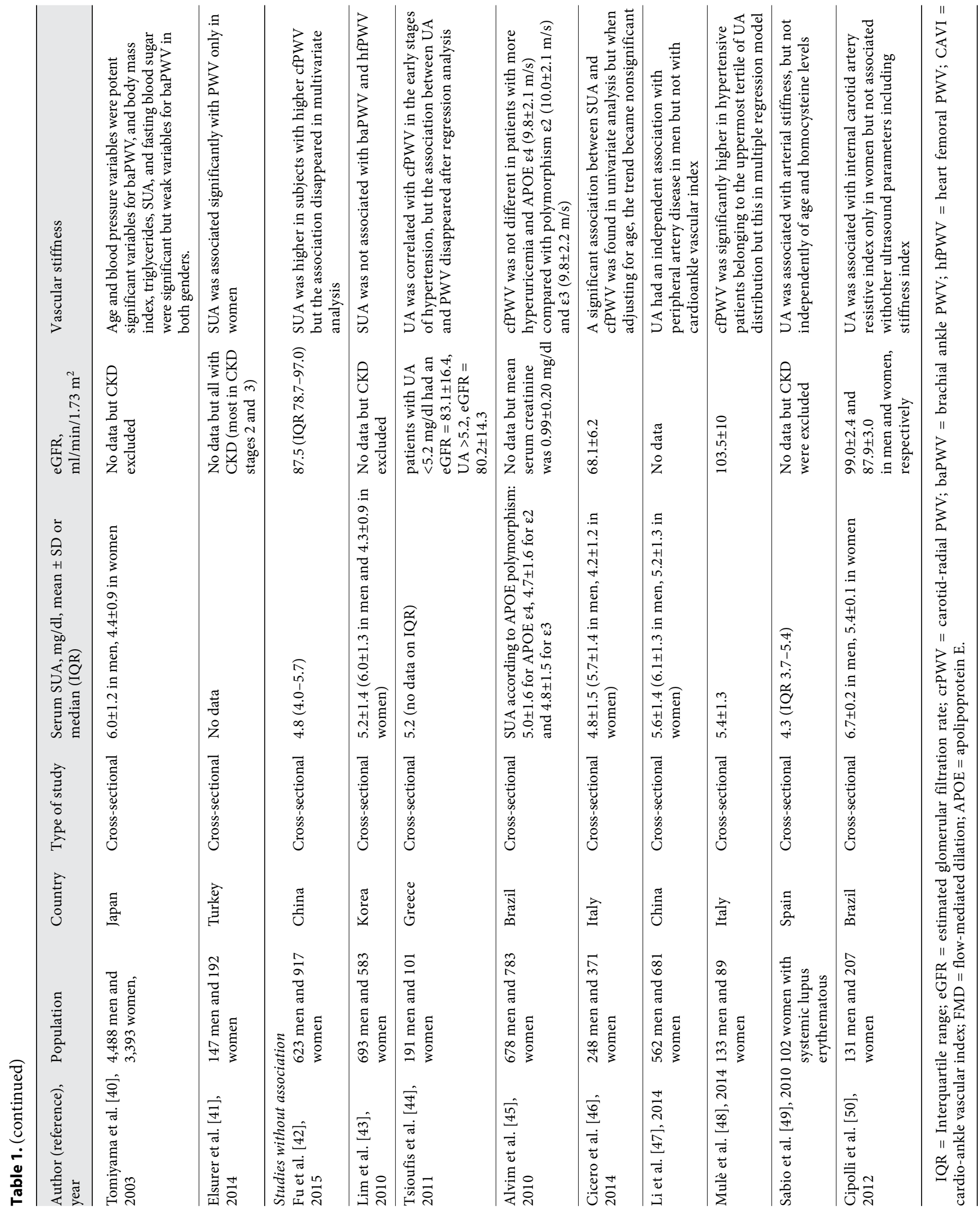


ment with allopurinol had a small but significant regression of left ventricular mass, but there were no changes in PWV at 9 months in CKD or IHD patients. Nevertheless, allopurinol significantly reduced AI in CKD and IHD patients, which was statistically significant at 9 months. The authors suggest that allopurinol caused a significant reduction in AI and improved endothelial function without a significant effect on BP suggesting improved arterial compliance [35]. It has been demonstrated that different medications to lower SUA have varied effects on vascular stiffness. In a 1-year prospective comparative study, patients with gout assigned to allopurinol had a significant increase in cfPWV $(16.8 \pm$ $4.3 \mathrm{~m} / \mathrm{s}, \mathrm{p}=0.001$ as compared to baseline), but febuxostattreated patients experienced a beneficial yet opposite effect on cfPWV $(13.3 \pm 2.3 \mathrm{~m} / \mathrm{s}, \mathrm{p}=0.55)$, although both medications inhibited xanthine oxidase and resulted in effective reduction in SUA levels [36]. One small study of 10 patients with diabetes mellitus and 10 healthy controls did not find any changes in cfPWB or AI after a rapid infusion of intravenous urate oxidase, although SUA decreased significantly [37]. The small and inconclusive evidence from these interventional trials calls for further studies.

\section{Perspective and Conclusion}

Vascular stiffness provides a better understanding of the relationship between SUA, CKD and CVD. Further research is clearly required in order to establish the effect of lowering SUA on cardiovascular and renal endpoints. In this regard, vascular stiffness assessed with PWV may be a reproducible, valid, short-term, and useful surrogate endpoint. Although there is a clear and proposed link between SUA and vascular stiffness, it does not yet support the specific treatment of hyperuricemia to reduce kidney or cardiovascular outcomes. Nevertheless, there would seem to be sufficient evidence to warrant larger clinical trials to determine whether lowering SUA concentrations would be useful in the prevention or treatment of vascular stiffness and, subsequently, of cardiovascular and renal diseases.

\section{Disclosure Statement}

The authors have no financial conflicts of interest to declare.

\section{References}

1 Koenig W, Meisinger C: Uric acid, type 2 diabetes, and cardiovascular diseases: fueling the common soil hypothesis? Clin Chem 2008; 54 : 231-233.

2 Gaffo AL, Edwards NL, Saag KG: Gout. Hyperuricemia and cardiovascular disease: how strong is the evidence for a causal link? Arthritis Res Ther 2009;11:240.

3 Madero M, Sarnak MJ, Wang X, Greene T, Beck GJ, Kusek JW, et al: Uric acid and longterm outcomes in CKD. Am J Kidney Dis 2009;53:796-803.

4 Safar ME, London GM: Therapeutic studies and arterial stiffness in hypertension: recommendations of the European society of hypertension. The clinical committee of arterial structure and function. Working group on vascular structure and function of the European society of hypertension. J Hypertension 2000; 18:1527-1535.

5 Blacher J, Pannier B, Guerin AP, et al: Carotid arterial stiffness as a predictor of cardiovascular and all-cause mortality in end-stage renal disease. Hypertension 1998; 32:570-574.

6 Bank AJ, Wang H, Holte JE, Mullen K, Shammas R, Kubo SH: Contribution of collagen, elastin, and smooth muscle to in vivo human brachial artery wall stress and elastic modulus. Circulation 1996;94:32633270 .
7 Mitchell GF, van Buchem MA, Sigurdsson S, Gotal JD, Jonsdottir MK, Kjartansson Ó, et al: Arterial stiffness, pressure and flow pulsatility and brain structure and function: the age, gene/environment susceptibility - Reykjavik study. Brain 2011;134(pt 11):3398-3407.

8 Sedaghat S, Mattace-Raso FU, Hoorn EJ, Uitterlinden AG, Hofman A, Ikram MA, et al: Arterial stiffness and decline in kidney function. Clin J Am Soc Nephrol 2015;10:21902197.

9 Steppan J, Barodka V, Berkowitz DE, Nyhan D: Vascular stiffness and increased pulse pressure in the aging cardiovascular system. Cardiol Res Pract 2011;2011:263585.

10 Safar ME, London GM, Plante GE: Arterial stiffness and kidney function. Hypertension 2004;43:163-168.

11 Ichihara A, Hayashi M, Kaneshiro Y, Takemitsu T, Homma K, Kanno Y, et al: Low doses of losartan and trandolapril improve arterial stiffness in hemodialysis patients. Am J Kidney Dis 2005;45:866-874.

12 Laurent S, Cockcroft J, Van Bortel L, Boutouyrie P, Giannattasio C, Hayoz D, et al: Expert consensus document on arterial stiffness: methodological issues and clinical applications. Eur Heart J 2006;27:25882605.

13 Bozec E, Girerd N: Carotid-femoral pulse wave velocity: an urgent need for a harmoni- zation of denominations. Am J Hypertens 2015;28:951.

14 Fantin F, Mattocks A, Bulpitt CJ, Banya W, Rajkumar C: Is augmentation index a good measure of vascular stiffness in the elderly? Age Ageing 2007;36:43-48.

15 Mackenzie IS, Wilkinson IB, Cockcroft JR: Assessment of arterial stiffness in clinical practice. QJM 2002;95:67-74.

16 Peralta CA, Jacobs DR Jr, Katz R, Ix JH, Madero M, Duprez DA, et al: Association of pulse pressure, arterial elasticity, and endothelial function with kidney function decline among adults with estimated GFR $>60 \mathrm{~mL} /$ $\mathrm{min} / 1.73 \mathrm{~m}(2)$ : the multi-ethnic study of atherosclerosis. Am J Kidney Dis 2012;59: 41-49.

17 Madero M, Wassel CL, Peralta CA, Najjar SS, Sutton-Tyrrell K, Fried L, et al: Cystatin C associates with arterial stiffness in older adults. J Am Soc Nephrol 2009;20:1086-1093.

18 Madero M, Peralta C, Katz R, Canada R, Fried L, Najjar S, et al: Association of arterial rigidity with incident kidney disease and kidney function decline: the health $\mathrm{ABC}$ study. Clin J Am Soc Nephrol 2013;8:424-433.

19 Enomoto A, Kimura H, Chairoungdua A, Shigeta Y, Jutabha P, Cha SH, et al: Molecular identification of a renal urate anion exchanger that regulates blood urate levels. Nature 2002;417:447-452. 
20 Sánchez-Lozada LG, Soto V, Tapia E, AvilaCasado C, Sautin YY, Nakagawa T, et al: Role of oxidative stress in the renal abnormalities induced by experimental hyperuricemia. Am J Physiol Renal Physiol 2008;295:F1134F1141.

21 Kanellis J, Watanabe S, Li JH, Kang DH, Li P, Nakagawa T, et al: Uric acid stimulates monocyte chemoattractant protein-1 production in vascular smooth muscle cells via mitogen-activated protein kinase and cyclooxygenase- 2 . Hypertension 2003;41:1287-1293.

22 Xie H, Sun J, Chen Y, Zong M, Li S, Wang Y: EGCG attenuates uric acid-induced inflammatory and oxidative stress responses by medicating the NOTCH pathway. Oxid Med Cell Longev 2015;2015:214836.

23 Arai $\mathrm{H}$, Hori S, Aramori I, Ohkubo H, Nakanishi S: Cloning and expression of a cDNA encoding an endothelin receptor. Nature 1990;348:730-732.

24 Corry DB, Eslami P, Yamamoto K, Nyby MD, Makino H, Tuck ML: Uric acid stimulates vascular smooth muscle cell proliferation and oxidative stress via the vascular renin-angiotensin system. J Hypertens 2008;26:269-275.

25 Duca L, Blaise S, Romier B, Laffargue M, Gayral S, El Btaouri $\mathrm{H}$, et al: Matrix ageing and vascular impacts: focus on elastin fragmentation. Cardiovasc Res 2016;110:298-308.

26 Yamanaka $\mathrm{H}$, Osaka $\mathrm{M}$, Takayama $\mathrm{M}, \mathrm{Mu}$ nakata K, Nejima J, Katayama M: Age-adjusted level of circulating elastin as a cardiovascular risk factor in medical check-up individuals. J Cardiovasc Med (Hagerstown) 2014;15: 364-370.

27 Watanabe S, Kang DH, Feng L, Nakagawa T, Kanellis J, Lan H, et al: Uric acid, hominoid evolution, and the pathogenesis of salt-sensitivity. Hypertension 2002;40:355-360.

28 Borghi C, Rosei EA, Bardin T, Dawson J, Dominiczak A, Kielstein JT, et al: Serum uric acid and the risk of cardiovascular and renal disease. J Hypertens 2015;33:1729-1741; discussion 1741.

29 Mehta T, Nuccio E, McFann K, Madero M, Sarnak MJ, Jalal D: Association of uric acid with vascular stiffness in the Framingham heart study. Am J Hypertens 2015;28:877883.

30 Kuo CF, Yu KH, Luo SF, Ko YS, Wen MS, Lin YS, et al: Role of uric acid in the link between arterial stiffness and cardiac hypertrophy: a cross-sectional study. Rheumatology (Oxford) 2010;49:1189-1196.

31 Fang JI, Wu JS, Yang YC, Wang RH, Lu FH, Chang CJ: High uric acid level associated with increased arterial stiffness in apparently healthy women. Atherosclerosis 2014;236: 389-393.

32 Bian S, Guo H, Ye P, Luo L, Wu H, Xiao W: Serum uric acid level and diverse impacts on regional arterial stiffness and wave reflection. Iran J Public Health 2012;41:33-41.

33 Kao MP, Ang DS, Gandy SJ, Nadir MA, Houston JG, Lang CC, et al: Allopurinol benefits left ventricular mass and endothelial dysfunction in chronic kidney disease. J Am Soc Nephrol 2011;22:1382-1389.

34 Szwejkowski BR, Gandy SJ, Rekhraj S, Houston JG, Lang CC, Morris AD, et al: Allopurinol reduces left ventricular mass in patients with type 2 diabetes and left ventricular hypertrophy. J Am Coll Cardiol 2013;62:22842293.

35 Rekhraj S, Gandy SJ, Szwejkowski BR, Nadir MA, Noman A, Houston JG, et al: High-dose allopurinol reduces left ventricular mass in patients with ischemic heart disease. J Am Coll Cardiol 2013;61:926-932.

36 Tausche AK, Christoph M, Forkmann M, Richter U, Kopprasch S, Bielitz C, et al: As compared to allopurinol, urate-lowering therapy with febuxostat has superior effects on oxidative stress and pulse wave velocity in patients with severe chronic tophaceous gout. Rheumatol Int 2014;34:101-109.

37 Waring WS, Convery a, Mishra V, Shenkin a, Webb DJ, Maxwell SR: Uric acid reduces exercise-induced oxidative stress in healthy adults. Clin Sci (Lond) 2003;105:425-430.

38 Park JS, Kang S, Ahn CW, Cha BS, Kim KR, Lee HC: Relationships between serum uric acid, adiponectin and arterial stiffness in postmenopausal women. Maturitas 2012;73: 344-348.

39 Zhang J, Xiang G, Xiang L, Sun H: Serum uric acid is associated with arterial stiffness in men with newly diagnosed type 2 diabetes mellitus. J Endocrinol Invest 2014;37:441-447.

40 Tomiyama H, Yamashina A, Arai T, Hirose K, Koji Y, Chikamori T, et al: Influences of age and gender on results of noninvasive brachial-ankle pulse wave velocity measurement - a survey of 12517 subjects. Atherosclerosis 2003;166:303-309.
41 Elsurer R, Afsar B: Serum uric acid and arterial stiffness in hypertensive chronic kidney disease patients: sex-specific variations. Blood Press Monit 2014;19:271-279.

42 Fu S, Luo L, Ye P, Xiao W: Multimarker analysis for new biomarkers in relation to central arterial stiffness and hemodynamics in a Chinese community-dwelling population. Angiology 2015;66:950-956.

43 Lim JH, Kim YK, Kim YS, Na SH, Rhee MY, Lee MM: Relationship between serum uric acid levels, metabolic syndrome, and arterial stiffness in Korean. Korean Circ J 2010;40: 314-320.

44 Tsioufis C, Kyvelou S, Dimitriadis K, Syrseloudis D, Sideris S, Skiadas I, et al: The diverse associations of uric acid with lowgrade inflammation, adiponectin and arterial stiffness in never-treated hypertensives. J Hum Hypertens 2011;25:554-559.

45 Alvim RO, Freitas SR, Ferreira NE, Santos PC Cunha RS, Mill JG, et al: APOE polymorphism is associated with lipid profile, but not with arterial stiffness in the general population. Lipids Health Dis 2010;9:128.

46 Cicero AF, Salvi P, D'Addato S, Rosticci M, Borghi C: Association between serum uric acid, hypertension, vascular stiffness and subclinical atherosclerosis: data from the Brisighella heart study. J Hypertens 2014;32:57-64.

$47 \mathrm{Li} \mathrm{Y,} \mathrm{Lu} \mathrm{J,} \mathrm{Wu} \mathrm{X,} \mathrm{Yang} \mathrm{C:} \mathrm{Serum} \mathrm{uric} \mathrm{acid}$ concentration and asymptomatic hyperuricemia with subclinical organ damage in general population. Angiology 2014;65:634-640.

48 Mulè G, Riccobene R, Castiglia A, D'Ignoto F, Ajello E, Geraci G, et al: Relationships between mild hyperuricaemia and aortic stiffness in untreated hypertensive patients. Nutr Metab Cardiovasc Dis 2014;24:744-750.

49 Sabio JM, Vargas-Hitos JA, Mediavilla JD, Navarrete-Navarrete N, Zamora-Posadas M, Pérez-Vicente S, et al: Correlation of asymptomatic hyperuricaemia and serum uric acid levels with arterial stiffness in women with systemic lupus erythematosus without clinically evident atherosclerotic cardiovascular disease. Lupus 2010;19:591-598.

50 Cipolli JA, Ferreira-Sae MC, Martins RP, PioMagalhães JA, Bellinazzi VR, Matos-Souza JR, et al: Relationship between serum uric acid and internal carotid resistive index in hypertensive women: a cross-sectional study. BMC Cardiovasc Disord 2012;12:52. 